\title{
Cuidados do terapeuta ocupacional na introduçáo de recursos de Comunicação Alternativa no ambiente hospitalar
}

\author{
Janaína Santos Nascimento ${ }^{\mathrm{a}}$, Juliana Mannini ${ }^{\mathrm{a}}$, Miryam Bonadiu Pelosi ${ }^{\mathrm{a}}$, \\ Mariana Mapelli de Paiva ${ }^{\mathrm{b}}$ \\ aDepartamento de Terapia Ocupacional, Universidade Federal do Rio de Janeiro - UFRJ, Rio de Janeiro, RJ, \\ Brasil.

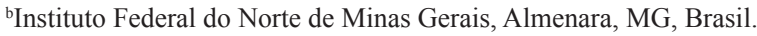

\begin{abstract}
Resumo: Introdução: A Comunicação Alternativa e Ampliada (CAA) é uma das áreas da Tecnologia Assistiva, e a sua introdução, no ambiente hospitalar, vem contribuindo de forma decisiva para o cuidado e a integração dos pacientes com dificuldades de fala ou escrita. No entanto, para que a utilização dos recursos de CAA seja efetiva nesse ambiente, são imprescindíveis ações para a prevenção e controle das infecções hospitalares (IH). Objetivo: Descrever as estratégias relacionadas ao controle das IH e utilizadas para a introdução de recursos de CAA em um hospital universitário. Método: Apresenta-se como estratégia metodológica o relato de experiência a partir da vivência de cinco terapeutas ocupacionais, dos quais quatro residentes e um professor supervisor, no decorrer do trabalho de introdução dos recursos de CAA em um hospital universitário, no período de junho de 2012 a julho de 2014. Resultados: Os principais cuidados adotados foram: plastificar as pranchas impressas; envolver com plástico filme os computadores, tablets, comunicadores, caneta para tablet, mouse e acionador; proteger com sacos plásticos materiais de apoio para as atividades, como mesa e plano inclinado; fazer o transporte por meio de um carrinho plástico. Após o uso dos materiais, eles eram ensacados e encaminhados para limpeza e desinfecção no expurgo. Conclusão: Os dados mostraram a complexidade do uso de recursos de CAA no ambiente hospitalar pelos terapeutas ocupacionais e a necessidade de treinamento dos profissionais envolvidos em ações pela equipe da Comissão de Controle de Infecção Hospitalar (CCIH).
\end{abstract}

Palavras-chave: Equipamentos de Autoajuda, Terapia Ocupacional, Serviços Técnico-Hospitalares.

\section{Occupational therapist care in the introduction of Alternative Communication features in hospital environment}

\begin{abstract}
Introduction: Alternative and Extended Communication (CAA) is an area of assistive technology, and its introduction in the hospital environment has contributed decisively to the care and integration of patients with speech or writing difficulties. However, in order for the use of CAA resources to be effective in this environment, actions are essential to prevent and control Hospital Infections (HI). Objective: To describe the strategies related to the control of HI, used for the introduction of CAA resources on a in a university hospital. Method: It presents as methodological strategy the experience report, the descriptive and exploratory mode, based on the experience of five therapists occupational - four residents and a supervisor professor -, during the introductory work of CAA resource at a university hospital, from June 2012 to July 2014. Results: The main precautions adopted were: to laminate the printed boards; to wrap with plastic film computers, tablets, communicators, tablet pen, mouse and driver; protect with plastic bags support materials for activities such as table and inclined plane, and transport by
\end{abstract}

Autor para correspondência: Janaína Santos Nascimento, Coordenação do Curso de Terapia Ocupacional, Rua Prof. Rodolpho Paulo Rocco, s/n, Bloco K, Sala 17, Prédio do CCS, Cidade Universitária, Ilha do Fundão, CEP 21941-902, Rio de Janeiro, RJ, Brasil, e-mail: jananascimento.to@gmail.com

Recebido em Nov. 5, 2015; 1ª Revisão em Fev. 18, 2016; 2a Revisão em Abr. 13, 2016; Aceito em Abr. $26,2016$. 
means of a plastic cart. After the materials use, they were placed in plastic bags and sent for cleaning and disinfection the purge. Conclusion: The data showed the complexity of the use of CAA resources in the hospital environment by occupational therapists, and the need for training of professionals involved in actions by Hospital Infection Control Committees team (CCIH).

Keywords: Self-help Devices, Occupational Therapy, Hospital Technical Services.

\section{Introdução}

Os terapeutas ocupacionais são profissionais habilitados a avaliar as ocupaçóes, os fatores, as habilidades e os padróes de desempenho das pessoas, bem como o contexto e o ambiente em que desempenham suas atividades, trabalhando com o propósito de favorecer a saúde, o bem-estar e a participação na vida. $\mathrm{O}$ ambiente hospitalar é composto por seu espaço físico, mobiliário, equipamentos e por profissionais que prestam serviço às pessoas hospitalizadas. Já o contexto refere-se aos elementos que tanto compóem quanto circundam uma pessoa, como os pessoais, culturais, temporais e virtuais, e que, apesar de menos tangíveis do que os ambientes físicos e sociais, exercem uma forte influência sobre seu desempenho (AMERICAN..., 2014).

Dessa forma, no ambiente hospitalar, os pacientes que necessitam de cuidados de saúde e que estão permanente ou temporariamente incapacitados de se comunicar serão afetados pelo ambiente físico e social do hospital, pelo contexto e por seus próprios fatores, padrôes de desempenho e habilidades, que influenciarão na sua relação com o médico, enfermeiro, terapeutas e familiares, muitas vezes impossibilitando o atendimento de suas necessidades básicas e gerando dificuldades diagnósticas.

Quando os pacientes estão em um estágio de comunicação vulnerável, em que há falhas de comunicação entre o paciente e o interlocutor, gerando dificuldade de participação ativa do indivíduo no seu processo de recuperaçáo, desde o período de admissão até a alta, a introdução da Comunicação Alternativa e Ampliada (CAA) torna-se fundamental (THE JOINT..., 2010).

A CAA é uma das áreas da Tecnologia Assistiva, e a sua introdução, no ambiente hospitalar, vem contribuindo de forma decisiva para o cuidado e a integraçáo dos pacientes com dificuldades de fala ou escrita. Muitos profissionais podem estar envolvidos na atuação na área da CAA, dentre eles destacam-se os terapeutas ocupacionais (PELOSI; NASCIMENTO; SOUZA, 2015).

De maneira geral, o trabalho do terapeuta ocupacional tem sido descrito como importante para o enfrentamento da hospitalização e do adoecimento, à medida que auxilia na realização de afazeres saudáveis, no resgate ou na descoberta de novas capacidades e habilidades (SANTOS; DE CARLO, 2013). Para isso, os terapeutas ocupacionais usam ocupações e atividades selecionadas de forma terapêutica como métodos primários de intervenção (AMERICAN..., 2014).

$\mathrm{Na}$ área de CAA, o papel dos terapeutas ocupacionais perpassa pela avaliação do paciente sobre sua condição motora, capacidade cognitiva e sensorial, nível de alerta, motivação, desejo e necessidade de se comunicar. A partir disso, ocorre a indicaçáo do recurso a ser utilizado por cada paciente, a escolha da quantidade de símbolos a ser empregada, da técnica de seleção, do posicionamento ideal do recurso e do paciente (CANADIAN..., 2003).

A seleção de recursos e de estratégias que ampliem a comunicação dos pacientes hospitalizados representa um grande desafio e exige uma equipe habilitada, capaz de realizar um planejamento sistemático, e comprometida com o trabalho em grupo (DOWNEY; HAPP, 2013).

Soma-se a isso a necessidade de adoção de estratégias para a prevenção e controle das infecções hospitalares (IH), enfoque deste estudo, tendo em vista que estas podem oferecer risco significativo à saúde dos pacientes hospitalizados e dos profissionais (DONINI et al., 2013).

A IH é definida como aquela adquirida após a internação do usuário e que se manifesta durante a hospitalização, ou mesmo após a alta, quando comprovadamente tiver relação com a internação ou procedimentos hospitalares (BRASIL, 1992).

Algumas IH são evitáveis, outras não. As preveníveis são aquelas nas quais podemos interferir na cadeia de transmissão dos microrganismos por meio de medidas como lavagem das mãos, processamento dos artigos e superfícies, utilização dos equipamentos de proteção individual e medidas de antissepsia (PEREIRA et al., 2005).

As Comissóes de Controle de Infecção Hospitalar (CCIH) são os órgãos responsáveis, no hospital, pela criação, implantação, normatização e supervisão das medidas de prevenção e controle das IH (FERREIRA; BEZERRA, 2010; DONINI et al., 2013). As CCIH surgiram no país a partir de 1968 , inicialmente 
vinculadas a instituiçóes de ensino, mas, em 1976, o governo determinou a necessidade de sua criação em hospitais (OLIVEIRA; MARUYAMA, 2008).

As CCIH são compostas por diferentes profissionais de saúde, como médicos, enfermeiros e farmacêuticos, e têm como objetivo reduzir ao máximo a incidência e a gravidade das infecçóes (FERREIRA; BEZERRA, 2010; DONINI et al., 2013).

Para atingir esse objetivo, os membros das $\mathrm{CCIH}$ fazem uso de diferentes estratégias, como açóes educativas que incluem reuniôes e palestras, e o contato diário com os demais profissionais (AZAMBUJA; PIRES; VAZ, 2004; FERREIRA; BEZERRA, 2010).

Os problemas de IH merecem atenção contínua de todos que estão presentes no ambiente hospitalar e dos gestores de políticas públicas de saúde. A garantia de um ambiente seguro e a existência de uma equipe capacitada e em número suficiente são requisitos essenciais para a prestaçâo de cuidados aos pacientes e minimizar as IH (FERREIRA; BEZERRA, 2010). Além disso, o controle das IH é um dos indicadores de qualidade e ferramenta de uma gestáo adequada em ambientes hospitalares (OLIVEIRA, 2013).

Apesar dos aspectos citados, a literatura científica é escassa no que se refere aos cuidados necessários para o processo de introduçáo da CAA no ambiente hospitalar. Na literatura nacional, verifica-se que os estudos sobre a CAA não têm descrito esse processo, destacando apenas as questôes relacionadas à equipe, sua necessidade de treinamento (PELOSI, 2009; RADTKE et al., 2012; CERANTOLA; HAPP, 2012; DOWNEY; HAPP, 2013) e aos próprios recursos (MOTA; FRANÇA, 2010). Ademais, as investigaçôes sobre soluções quanto ao uso de diferentes recursos, considerando as IH, estáo direcionadas, em especial, aos cuidados com os brinquedos dentro do espaço hospitalar (FERREIRA; BEZERRA, 2010; GESSNER et al., 2013; CHADI et al., 2014).

Além disso, o papel do próprio terapeuta ocupacional será afetado considerando os ambientes. Naqueles com boa infraestrutura, com disponibilidade de recursos de CAA individuais para cada paciente, assim como suportes para os equipamentos, e com profissionais de apoio para os procedimentos de limpeza e desinfecção do material, o trabalho do terapeuta ocupacional estará mais focado nos sistemas de CAA, no ajuste dos recursos conforme as necessidades e as habilidades, e na formação dos demais membros da equipe.

Contudo, em situaçôes menos favoráveis, necessitará incluir em suas açóes uma série de procedimentos com vistas a preparar e desinfetar os equipamentos utilizados nos seus atendimentos. Desse modo, o objetivo deste trabalho é descrever as estratégias relacionadas ao controle das $\mathrm{IH}$ e utilizadas para a introdução de recursos de CAA em um hospital universitário da regiấo Sudeste do país.

\section{Método}

Apresenta-se como estratégia metodológica o relato de experiência, na modalidade descritiva, a partir da vivência de cinco terapeutas ocupacionais, dos quais quatro residentes e um professor supervisor, no decorrer do trabalho de introdução de recursos de CAA no ambiente hospitalar, no período de junho de 2012 a julho de 2014.

O hospital universitário, local da presente pesquisa, composto por 13 andares, é um dos espaços de assistência de uma universidade federal da regiáo Sudeste do país e no qual teve o serviço de Terapia Ocupacional impulsionado pelo início da graduação nessa área em 2009 e por projetos de pesquisa e extensão conduzidos por terapeutas ocupacionais docentes.

As atividades desses profissionais incluíram o atendimento, com abordagem individual e de grupo, de pacientes com idade acima de 14 anos, acometidos por diferentes patologias e internados nas mais diversas unidades ou enfermarias do referido hospital, dentre elas Cardiologia, Centros de Tratamento Intensivo, Clínica da Dor e Cuidados Paliativos, Clínica Médica, Clínica de Hemodiálise, Geriatria, Oncologia/Hematologia, Neurologia e Ortopedia. Somam-se a isso as açôes que contemplavam os cuidadores e a equipe do hospital.

Para a introdução do trabalho, as terapeutas ocupacionais participaram do treinamento para o uso dos equipamentos de CAA no curso de formação em Tecnologia Assistiva, que possui um módulo específico de Comunicação Alternativa, e das reunióes e treinamentos com a equipe do $\mathrm{CCIH}$ do hospital.

Além disso, as profissionais exploraram os diferentes recursos de CAA a serem utilizados por todos os pacientes, tais como: pranchas de comunicação impressa, tablets, comunicadores e computadores. Para favorecer o acesso dos pacientes, foi necessária também a seleção de outros materiais, como mouses, canetas para tablets e acionadores.

O projeto de pesquisa do qual foi extraído este relato de experiência foi aprovado pelo Comitê de Ética em Pesquisa com Seres Humanos, sob protocolo no 66/2011. 


\section{Resultados e Discussão}

Para a introdução de recursos de CAA, as terapeutas ocupacionais realizaram a avaliação, a orientação e o oferecimento de recursos de baixa e alta tecnologia aos pacientes com dificuldades comunicativas, transitória e permanente, atendidos no hospital.

Ressalta-se que a comunicação é essencial para que as pessoas exerçam suas atividades do dia a dia e desempenhem seus papéis ocupacionais. A gestão da comunicação das pessoas é um aspecto importante da vida e uma das áreas de intervenção da Terapia Ocupacional (AMERICAN..., 2014).

No entanto, para que a comunicação ocorresse de modo seguro, evitando a transmissão de um microrganismo de forma direta ou indireta, os profissionais envolvidos precisaram padronizar o processo de higienização e as açôes de limpeza e de desinfecção dos recursos de CAA. Essa problemática foi verificada a partir de reunióes sistemáticas com CCIH.

Dessa forma, este relato explicitará esses cuidados e, além disso, discutirá de maneira crítica as experiências vivenciadas, contribuindo para a ampliação das açôes dos terapeutas ocupacionais no ambiente hospitalar.

Inicialmente, os profissionais foram orientados em relação aos cuidados com o próprio corpo, como a utilização de unhas curtas, cabelos presos, a não utilizaçâo de acessórios como brincos, anéis e colares, e o uso do jaleco como a vestimenta mais adequada durante a assistência ao paciente.

Somado a isso, realizou-se o treinamento para a higienização adequada das mãos, conforme preconizado pelo manual da Agência Nacional de Vigilância Sanitária, exigiu-se uso de avental e luvas de procedimentos, como mostra a Figura 1, além da limpeza e da desinfecção dos recursos no expurgo (AGÊNCIA..., 2007).

As terapeutas ocupacionais foram orientadas também em relação às exigências para o atendimento de pacientes em isolamento. Durante o projeto, as intervençóes ocorreram com aqueles em isolamento de contato, exigindo cuidados como higienização das mãos, colocação do avental e uso de luvas.

Além disso, realizou-se avaliação conjunta com a equipe da $\mathrm{CCIH}$, com o objetivo de elaborar medidas mais adequadas para o transporte dos equipamentos no espaço hospitalar, como protegê-los de forma a não prejudicar a função do recurso e a utilização pelo paciente, e a realização da desinfecção após o uso, evitando danos.
Ressalta-se que os materiais utilizados em estabelecimentos de saúde são veículos de agentes infecciosos e que existe uma classificação que considera o risco potencial de aquisiçáo de infecção e indica as medidas relativas à esterilização e à desinfecção. Os materiais podem ser classificados como: críticos, quando penetram em tecidos estéreis; semicríticos, quando entram em contato com a membrana mucosa íntegra, ou pele não íntegra, e possuem alto risco de contaminação; náo críticos, quando entram em contato com a pele íntegra e possuem baixo risco de aquisição de infecção, podendo, portanto, ser lavados com água e sabão ou receber desinfecção de nível intermediário ou baixo (BRASIL, 1994).

Os recursos utilizados pelas terapeutas ocupacionais durante a pesquisa de CAA foram classificados como náo críticos, ou seja, apresentavam baixo risco de transmissão de infecção em virtude do contato apenas com a pele. No entanto, a parceria com a equipe da CCIH mostrou a necessidade de proteçáo dos recursos, mesmo quando o paciente não se encontrava em isolamento de contato.

Ressalta-se que a preparação dos recursos a serem utilizados nas intervenções precisava ser feita com antecedência para que os atendimentos ocorressem respeitando todos esses cuidados. Essa preparação acontecia em uma das salas do curso de graduaçáo em Terapia Ocupacional no Centro de Ciências da Saúde, com o apoio das bolsistas do projeto. Os recursos, depois de protegidos, eram separados em sacos plásticos, e o transporte acontecia por meio de um carrinho. O tempo médio para a realização desses procedimentos era de 1 hora.

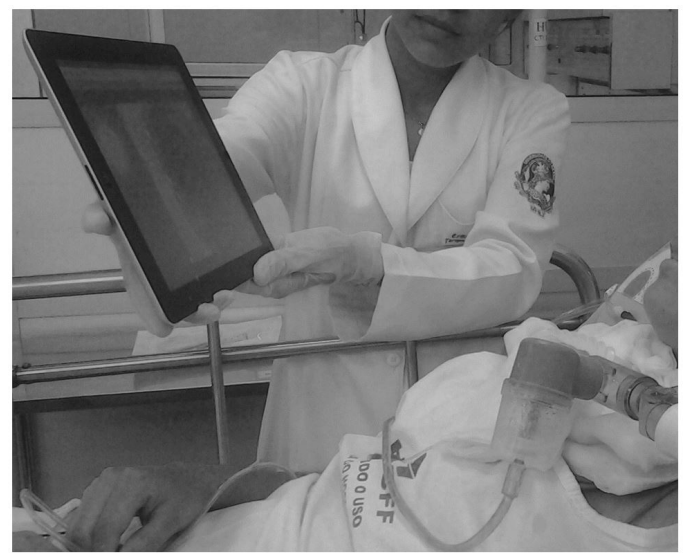

Figura 1. Terapeuta ocupacional usando os procedimentos-padrão exigidos. Fonte: imagem do autor. 
Em adição, houve a necessidade de aquisição de alguns materiais para dar suporte ao processo de preparação dos materiais, tais como: máquina plastificadora, plásticos, papel toalha, sacos e álcool $70 \%$.

As pranchas foram plastificadas, e os computadores, tablets e comunicadores, totalmente envolvidos com plástico filme. A forma de acesso do paciente também foi analisada, com a proteção da caneta para tablet, do mouse e do acionador com plástico filme.

Mota e França (2010) descreveram um estudo que envolveu pacientes com dificuldades comunicativas, internados nas Unidades de Terapia Intensiva, em que os cartôes utilizados para favorecer a comunicação também foram plastificados com o intuito de facilitar a posterior desinfecção com álcool.

Os materiais de apoio para as atividades, como mesa e plano inclinado, também precisaram ser cobertos com sacos plásticos. Evitou-se o uso de objetos de difícil limpeza, como os que apresentavam superfície irregular e pequenos orifícios.

Após a utilização dos recursos pelos pacientes, os equipamentos eram colocados em outro saco plástico e encaminhados para limpeza e desinfecção no expurgo, local destinado à limpeza, desinfecçáo e guarda dos materiais e roupas utilizados na assistência ao paciente.

Os procedimentos no expurgo eram iniciados pelo terapeuta com a lavagem das mãos com água e sabonete líquido, utilização de luvas e limpeza da bancada. Outras orientaçóes a serem seguidas pelas terapeutas ocupacionais consideraram a forma correta de retirar o plástico filme dos recursos, como mostra a Figura 2, evitando a contaminação, e, ainda, a maneira de realizar a desinfecção química, que era feita por meio da fricção, por 30 segundos, de todas as partes que compunham os recursos, com álcool $70 \%$. Essa técnica era repetida três vezes (AGÊNCIA..., 2013) e realizada ao final de cada atendimento.

Os procedimentos necessários para evitar a disseminação da IH mostraram a complexidade do uso de recursos de CAA no ambiente hospitalar e apontaram para a necessidade de treinamento dos profissionais envolvidos em ações nesse espaço. Ainda, a escolha dos recursos e dos materiais de apoio a serem utilizados em hospitais pelas terapeutas ocupacionais deve considerar o risco de transmissão de infecção, o tipo do material e a sua possibilidade de limpeza e de desinfecção.
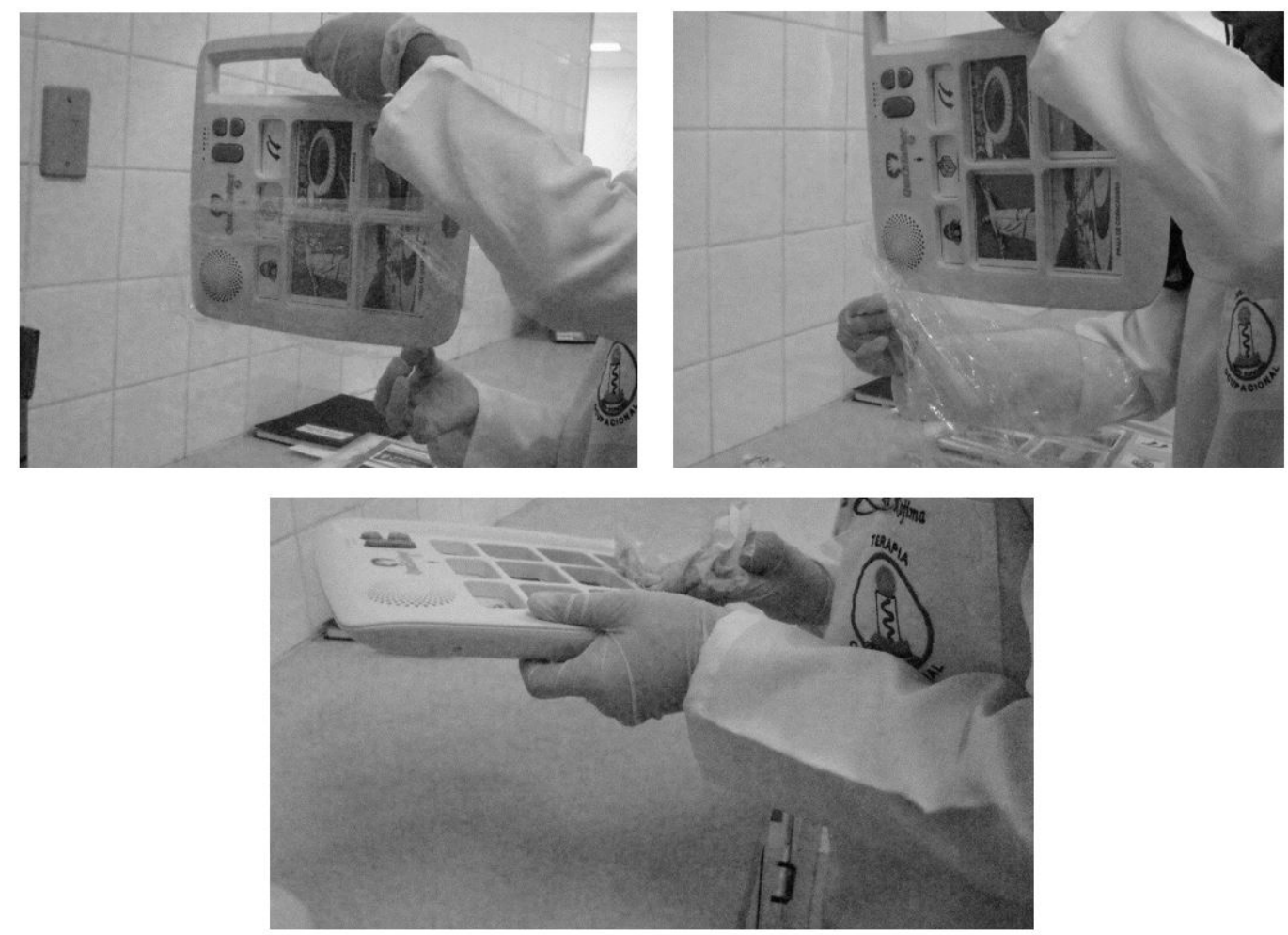

Figura 2. Retirada do plástico de proteção. Fonte: imagem do autor. 
A partir das orientaçóes do $\mathrm{CCIH}$, algumas modificaçóes precisaram ser implantadas. Os comunicadores, aparelhos em que as mensagens são pré-gravadas e soadas, ou sintetizadas a partir do comando do usuário, possuem vários níveis de gravação, cujo objetivo é permitir que o usuário, ou seu parceiro de comunicação, troque a prancha que está sendo utilizada por outra mais adequada ao assunto em pauta. A mudança de prancha não acontece automaticamente como nos tablets ou programas de computador; é necessário acessar uma fenda na lateral do equipamento para efetuar a troca. A partir da necessidade de proteção do recurso com plástico filme, os comunicadores empregados na pesquisa perderam a possibilidade de mudar de nível, limitando, assim, a sua utilização.

Outro recurso que precisou ser adequado foi o mouse do computador. $\mathrm{O}$ processo de proteger o fio do mouse mostrou-se complexo, e a retirada do plástico filme contaminava o equipamento. A solução adotada foi a substituição por um mouse sem fio.

As pranchas de comunicação também se tornaram um problema, pois os acompanhantes dos outros pacientes internados nas enfermarias as utilizavam para se comunicar com seus familiares ou as manuseavam por curiosidade.
Para solucionar essa questão, foram realizadas orientações sistemáticas aos familiares e demais acompanhantes, e as pranchas de comunicaçáo receberam páginas de alerta, como mostra a Figura 3.

As mesas de rodinha, que facilitavam o transporte dos equipamentos entre os andares do hospital, foram impedidas de entrar nos Centros de Terapia Intensiva em virtude de seu potencial de infecção cruzada por bactérias.

No ambiente hospitalar, o recurso terapêutico deve permitir a desinfecção entre o uso dos pacientes e possuir algumas características, como ser confeccionado em plástico rígido ou metal e náo poroso (CARDOSO; CORRÊA; MEDEIROS, 2005). Dessa forma, é importante considerar que, independente do objetivo do trabalho a ser realizado, torna-se necessária a escolha cuidadosa dos recursos que serão utilizados.

Outro aspecto significativo é que os materiais que não podem ser higienizados devem ser substituídos por outros mais adequados, por exemplo, os jogos de dominó de madeira, ou que sejam utilizados exclusivamente por um único paciente, como no caso de revistas.

Como alternativa, os materiais podem ser elaborados pelas próprias terapeutas ocupacionais, respeitando as orientaçôes da CCIH, como mostra a Figura 4.

\section{$\mathbb{1}$

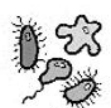 \\ PERIGO MICRÓBIOS}

\section{異

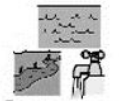 \\ + SABAO \\ LAVE AS MÃOS COM ÁGUA E SABÃO DEPOIS}
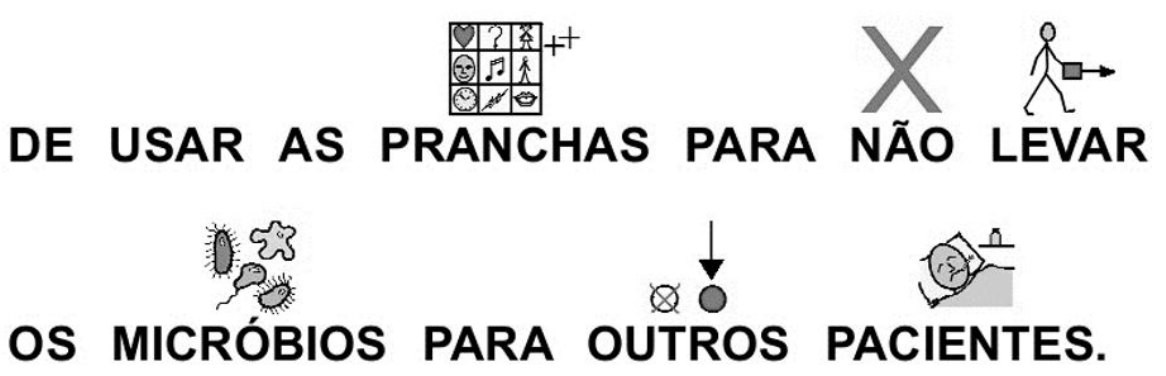

Figura 3. Capa de alerta para as pranchas de comunicação hospitalar. Fonte: imagem do autor. 


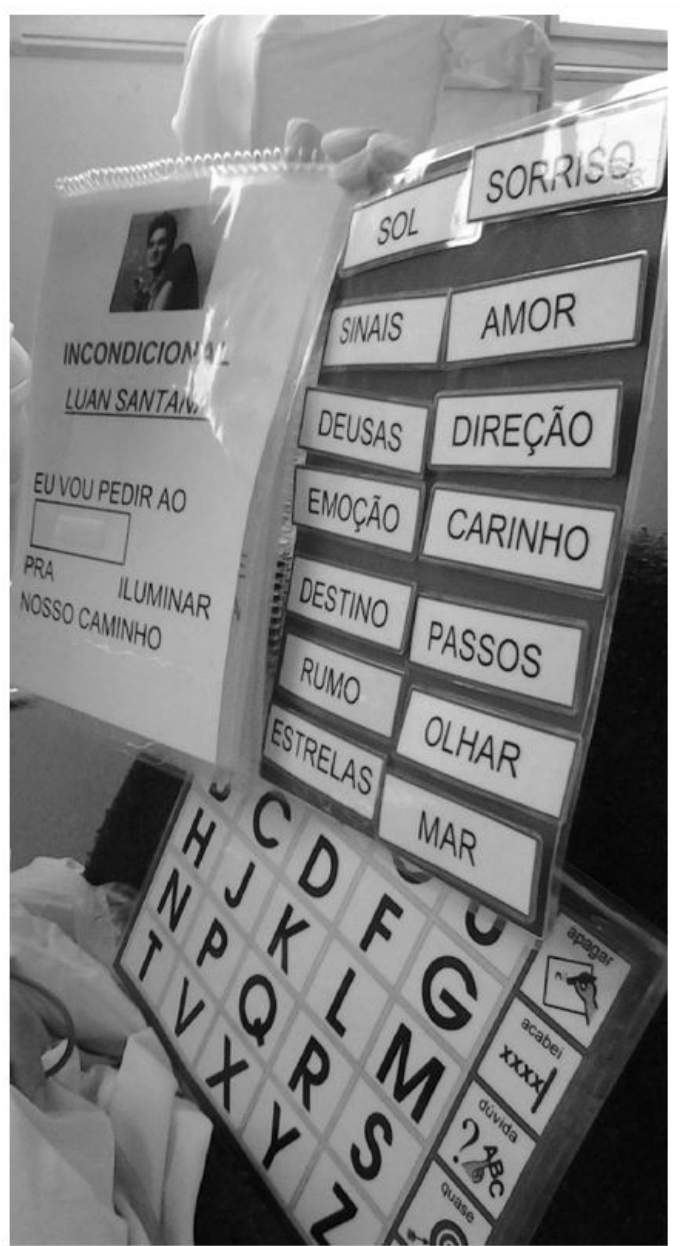

Figura 4. Atividade adaptada para completar letra de música para uso no hospital. Fonte: imagem do autor.

\section{Conclusão}

Os dados mostraram a complexidade do uso de recursos de CAA no ambiente hospitalar e a necessidade de treinamento dos profissionais envolvidos em açóes dentro desse ambiente pela equipe do $\mathrm{CCIH}$, em especial pelo fato de cada hospital ter especificidades próprias.

Além disso, apontaram para a necessidade de o terapeuta ocupacional estar preparado para atuar em diferentes clínicas e em situações adversas como nos Centros de Terapia Intensiva, respeitando as exigências e os cuidados essenciais para o atendimento do paciente, e a escolha cuidadosa dos recursos que serão utilizados, independente do objetivo do trabalho a ser realizado pelo profissional.

Este estudo teve como limitaçáo ser do tipo relato de experiência. No entanto, apesar disso, espera-se que os resultados produzidos favoreçam a troca de conhecimentos em relação aos cuidados para introdução dos recursos de CAA. E, ainda, orientem outros terapeutas ocupacionais que têm interesse em trabalhar fazendo uso desse processo, sensibilizem sobre a necessidade dessa parceria com o $\mathrm{CCIH}$, para que sua prática no ambiente hospitalar ocorra de forma segura e adequada, e direcionem para o desenvolvimento de outras pesquisas com diferentes abordagens sobre essa temática.

\section{Referências}

AGÊNCIA NACIONAL DE VIGILÂNCIA SANITÁRIA - ANVISA. Higienização das mãos em serviços de saúde. Brasília: ANVISA, 2007.

AGÊNCIA NACIONAL DE VIGILÂNCIA SANITÁRIA - ANVISA. Nota Técnica $n^{\circ}$ 01/2013: medidas de prevenção e controle de infecções por enterobactérias multiresistentes. Brasília, DF, 17 abr. 2013. Disponível em: <http://portal.anvisa.gov.br/wps/wcm/ connect/ea4d4c004f4ec3b98925d9d785749fbd/ Microsoft+Word+-+NOTA+T\%C3\%89CNICA+ ENTEROBACTERIAS +17+04+2013\%281\%29. pdf?MOD=AJPERES $>$. Acesso em: 30 ago. 2015.

AMERICAN OCCUPATIONAL THERAPY ASSOCIATION - AOTA. Occupational therapy practice framework: domain and process. American Journal of $\mathrm{Oc}$ cupational Therapy, Bethesda, v. 68, n. 6, p. 1-43, 2014.

AZAMBUJA, E. P.; PIRES, D. P.; VAZ, M. R. C. Prevençấo e controle da infecçấo hospitalar: as interfaces com o processo de formaçáo do trabalhador. Texto \& Contexto - Enfermagem, Florianópolis, v. 13, p. 79-85, 2004. Número Especial.

BRASIL. Portaria no 930, de 27 agosto de 1992. Expede instruçōes para o controle e prevenção das infecçôes hospitalares. Diário Oficial [da] República Federativa do Brasil, Brasília, DF, 04 set. 1992. Disponível em: <http:// www.anvisa.gov.br/legis/portarias/930_92.htm>. Acesso em: 30 ago. 2015.

BRASIL. Ministério da Saúde. Secretaria de Assistência à Saúde. Departamento de Assistência e Promoção à Saúde. Coordenação de Controle de Infecção Hospitalar. Processamento de artigos e superficies em estabelecimentos de saúde. Brasília, 1994. Disponível em: <http://www. anvisa.gov.br/servicosaude/controle/processamento_artigos.pdf $>$. Acesso em: 12 fev. 2016.

CANADIAN ASSOCIATION OF OCCUPATIONAL THERAPISTS POSITION STATEMENT - COAT. Assistive Technology and Occupational Therapy. Canadian Journal of Occupational Therapy, Ottowa, v. 70, n. 2, p. 113-118, 2003.

CARDOSO, M. F. S.; CORREA, L.; MEDEIROS, A. C. T. A higienização dos brinquedos no ambiente hospitalar. Revista Prática Hospitalar, São Paulo, ano VII, n. 42, p. 170-72, 2005.

CERANTOLA, C.; HAPP, M. Transitional Care for Communication Impaired Older Adults: ICU to Home. 
Geriatric Nursing, Nova York, v. 33, n. 6, p. 489-492, 2012.

CHADI, P. F. et al. Avaliação dos procedimentos de higienização dos brinquedos infantis e das brinquedotecas nacionais. Revista da Universidade Vale do Rio Verde, Três Coraçôes, v. 12, n. 2, p. 296-305, 2014.

DONINI, C. et al. O. A atuaçáo do(a) enfermeiro(a) no controle de infecção hospitalar: um relato de experiência. Revista Vivências, Erechim, v. 9, n. 16, p. 10-19, 2013.

DOWNEY, D.; HAPP, M. B. The need for nurse training to promote improved patient-provider communication for patients with complex communication needs. Perspectives on Augmentative and Alternative Communication, Rockville, v. 22, n. 2, p. 112-119, 2013. Disponível em: <http://asha.http.internapcdn.net/asha_vitalstream_com/pubs/SIG12AAC/22_2/fullissue.pdf>. Acesso em: 05 out. 2015 .

FERREIRA, R. S.; BEZERRA, C. M. F. Atuação da Comissão de Controle Infecção Hospitalar (CCIH) na redução da infecção: um estudo no hospital da criança Santo Antônio. Norte Cientifico, Boa Vista, v. 5, n. 1, p. 29-45, 2010. Disponível em: <http:// www.researchgate.net/publication/267414746_ATuAO_DA_COMISSO_DE_CONTROLE_INfECO_HOSPITALAR_\%28CCIH\%29_NA_REDuO_ DA_INfECO_uM_ESTuDO_NO_HOSPITAL_DA_ CRIANA_SANTO_ANTNIO>. Acesso em: 07 out. 2015.

GESSNER, R. et al. Protocolo de desinfecção de brinquedos em unidade de internação pediátrica: vivência acadêmica de enfermagem. Ciência, Cuidado e Saúde, Maringá, v. 12, n. 1, p. 184-88, 2013.

MOTA, G. P.; FRANÇA, F. C. V. Comunicação não verbal em unidade de terapia intensiva: validação de um método alternativo. Revista Brasileira de Ciências da Saúde, João Pessoa, v. 1, n. 21, p. 39-48, 2010.
OLIVEIRA, R. A hotelaria hospitalar e o controle de infecção. Journal of infection control, St. Louis, v. 2, n. 3, p. 101-102, 2013.

OLIVEIRA, R.; MARUYAMA, S. A. T. Controle de infecção hospitalar: histórico e papel do estado. Revista Eletrônica de Enfermagem, Goiânia, v. 3, n. 10, p. 775783, 2008. Disponível em: <http://www.fen.ufg.br/ fen_revista/v10/n3/pdf/v10n3a23.pdf>. Acesso em: 15 ago. 2015 .

PELOSI, M. B. Tecnologias em Comunicação Alternativa sob o enfoque da Terapia Ocupacional. In: DELIBERATO, D.; GONÇALVES, E. C.; MACEDO, E. C. (Org.). Comunicação alternativa: teoria, prática, tecnologias e pesquisa. São Paulo: Memnon Edições Científicas, 2009. p. 163-173.

PELOSI, M. B.; NASCIMENTO, J. S.; SOUZA, V. L. V. Pacientes hospitalizados e a Comunicação Alternativa e Ampliada. In: CHUN, R. Y. S.; REILY, L.; MOREIRA, E. C. (Org.). Comunicação alternativa: ocupando territórios. São Carlos: Marquezine \& Manzini, 2015. p. 195-210.

PEREIRA, M. S. et al. A infecção hospitalar e suas implicaçóes para o cuidar da enfermagem. Texto \& Contexto - Enfermagem, Florianópolis, v. 2, n. 14, p. 250-7, 2005.

RADTKE, J. V.; TATE, J. A.; HAPP, M. B. Nurses perceptions of communication training in the ICU. Intensiveand Critical Care Nursing, Edimburgo, v. 28, n. 2, p. 16-25, 2012.

SANTOS, C. A. V.; DE CARLO, M. M. R. P. Hospital como campo de práticas: revisão integrativa da literatura e a terapia ocupacional. Cadernos de Terapia Ocupacional da UFSCar, São Carlos, v. 21, n. 1, p. 99-107, 2013

THE JOINT COMMISSION. Advancing effective communication, cultural competence, patient and family-centered care: a roadmap for hospitals. Oakbrook Terrace: The Joint Commission, 2010.

\section{Contribuição dos Autores}

Todos os autores foram responsáveis pela concepção, redação e revisão do texto, organização de fontes e análises. Todos os autores aprovaram a versão final do texto.

\section{Fonte de Financiamento}

CNPq: 476378/2011-7 - Edital UNIVERSAL. 